\title{
The Study of Operation Modes and Control Strategies of a Multidirectional MC for Battery Based System
}

\author{
Saman Toosi, ${ }^{1}$ Norhisam Misron, ${ }^{1,2}$ Tsuyoshi Hanamoto, ${ }^{3}$ Ishak Aris, ${ }^{1}$ \\ Mohd Amran Mohd Radzi, ${ }^{1}$ and Hiroaki Yamada ${ }^{4}$ \\ ${ }^{1}$ Department of Electrical \& Electronic Engineering, Faculty of Engineering, Universiti Putra Malaysia (UPM), \\ 43400 Serdang, Selangor, Malaysia \\ ${ }^{2}$ Institute of Advanced Technology (ITMA), Universiti Putra Malaysia (UPM), 43400 Serdang, Selangor, Malaysia \\ ${ }^{3}$ Department of Biological Functions Engineering, Graduate School of Life Science and Systems Engineering, \\ Kyushu Institute of Technology, 2-4 Hibikino, Wakamatsu-ku, Kitakyushu 808-0916, Japan \\ ${ }^{4}$ Graduate School of Science and Engineering, Yamaguchi University, 2-16-1 Tokiwadai, Ube-shi, Yamaguchi 755-8611, Japan \\ Correspondence should be addressed to Norhisam Misron; norhisam@upm.edu.my
}

Received 8 April 2015; Revised 13 June 2015; Accepted 23 June 2015

Academic Editor: Xiaosong Hu

Copyright (C) 2015 Saman Toosi et al. This is an open access article distributed under the Creative Commons Attribution License, which permits unrestricted use, distribution, and reproduction in any medium, provided the original work is properly cited.

\begin{abstract}
To enhance the performance of stand-alone battery based system and to achieve the continuous power transmission, the behavior of multidirectional matrix converter (MDMC) has been analyzed in different operation modes. A systematic method interfacing a renewable source, a storage battery, and a load is proposed for a stand-alone battery based power system (SABBPS) to utilize the MDMC as PWM converter, inverter, or PWM converter and inverter in different operation modes. In this study, the Extended Direct Duty Pulse Width Modulation (EDDPWM) technique has been applied to control the power flow path between the renewable source, load, and the battery. Corresponding to generator voltage, input frequency, and loads demands, several operating states and control strategies are possible. Therefore, the boundaries and distribution of operation modes are discussed and illustrated to improve the system performance. The mathematical equation of the EDDPWM under different operation modes has been derived to achieve the maximum voltage ratio in each mode. The theoretical and modulation concepts presented have been verified in simulation using MATLAB and experimental testing. Moreover, the THD, ripple, and power flow direction have been analyzed for output current to investigate the behavior of system in each operation mode.
\end{abstract}

\section{Introduction}

Renewable sources, such as hydro, solar, and wind, have the potential to play an important role in providing energy with sustainability to the vast populations of the world who do not have access to clean energy. Currently the stand-alone power system supplies the local villages or individual users in remote area where the grid extension is difficult or not economical. In stand-alone renewable power system storage elements such as battery or supercapacitor are used to supply power to the loads continuously [1]. The complexity of the control system remarkably rises by increasing the number of input sources as several separate converters are employed to control the power flow direction between the input ports and output ports of system. The type and number of power electronic converters change based on the type and number of energy sources and loads.

Multi-input DC-DC converter has been proposed to combine several types of energy sources and to obtain a desired DC output voltage [2]. This type of converter is commonly employed in the hybrid electric vehicles [3] and renewable power system to stabilize the voltage and frequency of system [4].

Several schemes of converter with two source inputs and single output have been proposed for the stand-alone hybrid renewable energy system in order to increase the power quality and reliability of system $[5,6]$. A double-input sources' single-output source power converter was developed to combine the energy sources of wind and solar in one power system [5]. However, it will be difficult to acquire 
the regulated voltage output if one of the DC sources is diminished, since the input voltage variation is significant. Therefore, Chen et al. (2001) proposed the high frequency transformer for double source system with isolated electrical circuit to reduce the voltage variation effect. These circuits have no charging path for the backup battery storage and could not control the power flow direction in system [6].

A multidirectional power converter (MDC) has been presented by Mei et al. (2006) for a battery based stand-alone hybrid renewable energy system to supply the battery and to control the power flow direction in a system. The MDC provided a battery storage path to supply the power demand in the days of deficit in solar and wind powers. However, the proposed MDC control was very complicated due to the number of modes and effect of power flow direction in high frequency isolated converter [7]. Later, the directional power converter is changed with bidirectional high-powerdensity DC-DC converter to interface with multiple energy storage components such as batteries and ultracapacitors. The proposed system needs multiwinding transformer for soft-switching conditions which cannot justify the unique features of low component count and compact structure for the integrated multiport converter [8].

Four-port DC/DC converter with bidirectional capability and isolated output feature has been proposed to reduce the size. Zero-voltage switching is introduced for all four main switches. Three of the four ports were tightly regulated by adjusting their independent duty-cycle values, while the fourth port was left unregulated to maintain the power balance for the system. In addition, a decoupling network is introduced to allow the separate controller design for each power port. This four-port converter is suitable for lowpower applications, where the energy storage is required while allowing tight load regulation [9]. However, the major problem is that the input and output port are DC and isolated transformer is essential for this structure.

In order to achieve maximum power tracking (MPT) through rotor speed control under varying wind speeds and control of the magnitude and the frequency of the load voltage, the new multiport system has been introduced based on two back-to-back voltage source converters (VSCs) with a battery energy storage system at their DC link. The proposed hybrid system was able to control the power flow, by which it controls the magnitude and the frequency of the load voltage [10]. The number of converters and passive components is still high and it is not suitable for the integrated multiport converter. Moreover, the size and cost increase and efficiency decreases due to multiple-stage conversion through the converters and transformers.

Most desired feature of multidirectional converter can be fulfilled by using matrix converter (MC) structure. In the MC, several bidirectional switches are used to couple the power sources to load side. With proper switching method, the bidirectional switches in $\mathrm{MC}$ can be utilized as inverter or rectifier. The first principle of $\mathrm{MC}$ control has been proposed by Venturini and Alesina in 1980, which is known as a "direct transfer function" approach [11]. They also extended the voltage ratio to 0.866 by using the third harmonic injection technique [12]. In 1983, Rodriguez introduced the novel control method based on "fictitious DC link" to reduce the complexity of direct method [13]. Ziogas et al. expanded Rodriguez's "fictitious DC link" idea to provide a rigorous mathematical explanation [14, 15]. Later, Kastner and Rodriguez (1985) used space vectors modulation in the switching control of matrix converters to increase the voltage ratio and reduce the number of switching states $[16,17]$. Several techniques have been reported which may have simplified the modulation [18-21] and solved the commutation problems in MC $[22,23]$. Although the SVPWM technique is the proper method for the three-phase matrix converters, the complexity of the implementation remarkably rises by increasing the number of inputs or outputs of MC and there is no attention to the input current.

To synthesize the sinusoidal input current with unity power factor and desired output voltage a new carrier based modulation method has been proposed based on the conventional space vector pulse modulation (SVPWM), with complex calculation [24]. In order to simplify the modulation method, the preliminary concepts of a new carrier based PWM strategy, named direct duty ratio PWM (DDPWM), are presented in [25]. They extended the DDPWM to various topologies of matrix converter and derived the control schemes for alternative structures converters in [26]. This modulation scheme is highly flexible and intuitive and it can be applied to any configuration of the matrix converter.

Toosi et al. in 2014 combined the characteristics of several separate converters in multidirectional matrix converter (MDMC) and proposed a novel modulation method that can control the power flow direction between each of input power supplies and output loads. The proposed modulation method is able to inject power from DC and AC supply to the load simultaneously by using the proper switching pattern. They validated that the MDMC with EDDPWM can work as modular converter, where the frequency and voltage of each output phase are independent of other output phases [27]. However, the system has been tested in simulation and operated in one mode.

Due to the high number of system parameters (i.e., number of inputs/outputs, load parameters and input filter, output frequency, switching frequency, modulation methods, and number of passive components) and the inherent differences between the converter topologies such as the maximum voltage transfer ratio, it is difficult to compare the proposed MDMC with the other multisource converters such as multidirectional power converter [7], ZVS bidirectional DC-DC converter [8], AC-DC-AC converter [28], multiport with several voltage sources converter [10], integrated fourport DC/DC converter [9], multi-input DC/DC converter [2], and double-input single-output power converter [5]. The main advantage of the MDMC for multi-input/output power system compared to other converters is its potential to decrease size of system by combining all characteristics of different rectifiers and inverters in one compact silicon converter and eliminating the passive component such as bulky capacitor and multiwinding transformer. In addition, the EDDPWM technique can provide bidirectional power flow, control input power factor, and synthesize the sinusoidal input current and output voltage waveforms. 


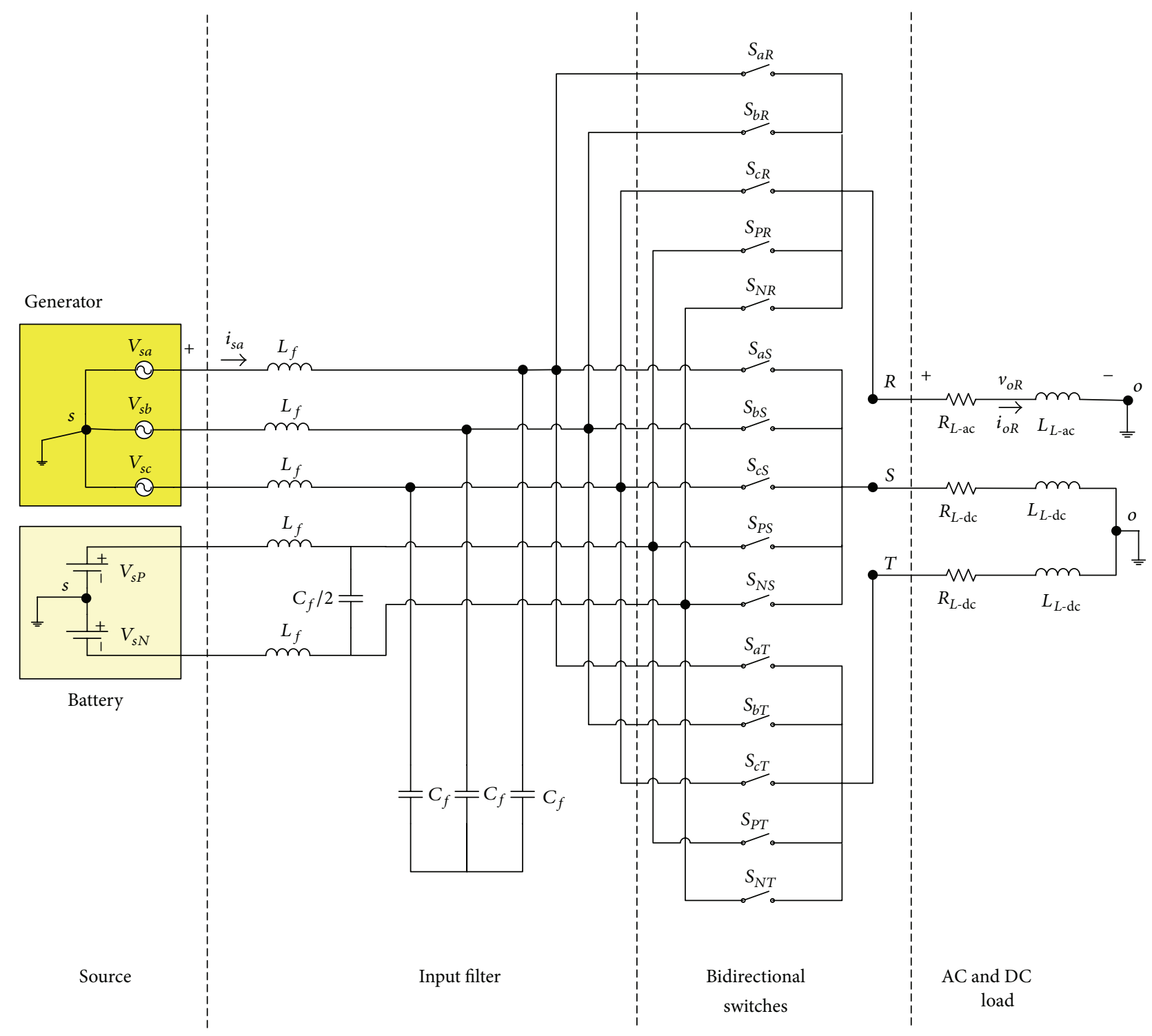

FIGURE 1: Multidirectional matrix converter circuit.

The voltage ratio of MDMC varied when the system switched from one operation mode to another mode. In order to keep the output voltage constant, the output voltage command should be calculated based on the type and number of input sources and output loads which are connected to the system. Accordingly, the behaviour of MDMC has been investigated in different operation modes to achieve the continuous power transmission and increase the efficiency by reducing the number of switches and calculating the maximum voltage ratio in each operation mode. By adjusting the time subinterval in EDDPWM method and analysing the power flow direction among the input and output ports of system, MDMC can work as inverter, PWM converter, or both PWM converter and inverter. In addition, this study is dedicated to analysis of the output current quality and derives the necessary equation of EDDPWM method in each operation mode.

\section{Principle of Extended Direct Duty PWM}

The operating principle of the EDDPWM has been described in [27], for MDMC with 15 bidirectional switches. Figure 1 indicates the circuit configuration of the MDMC in standalone battery based system (SABBS) when three-phase generator and two batteries are connected to the source side of the MDMC. The $R_{L-\mathrm{dc}}$ and $L_{L-\mathrm{dc}}$ and $R_{L-\mathrm{ac}}$ and $L_{L-\mathrm{ac}}$ indicate the DC and AC load, respectively.

According to Figures 2 and 3 , a switching period $T_{s}$ is divided into two time periods, $T_{c}$ and $T_{3}$. During $T_{c}$, the input phases of AC generator are connected to a corresponding 


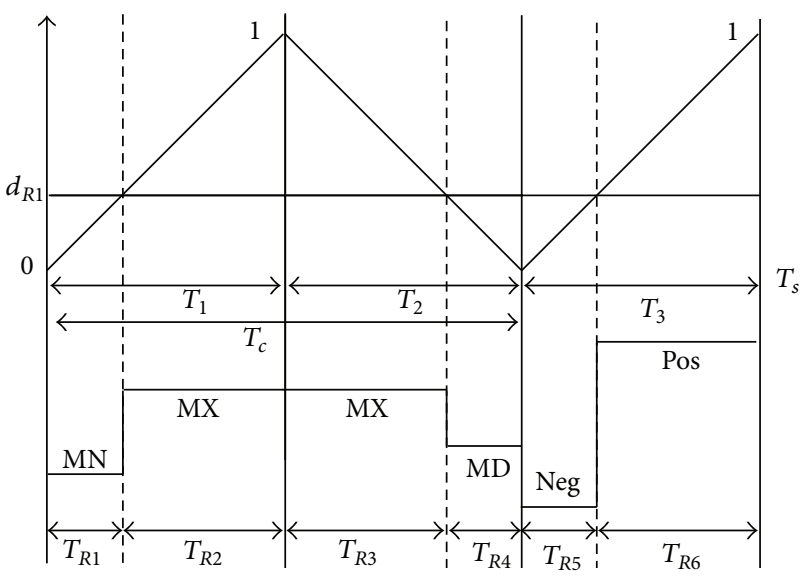

FIGURE 2: Switching pattern I, output $R$ phase switching state.

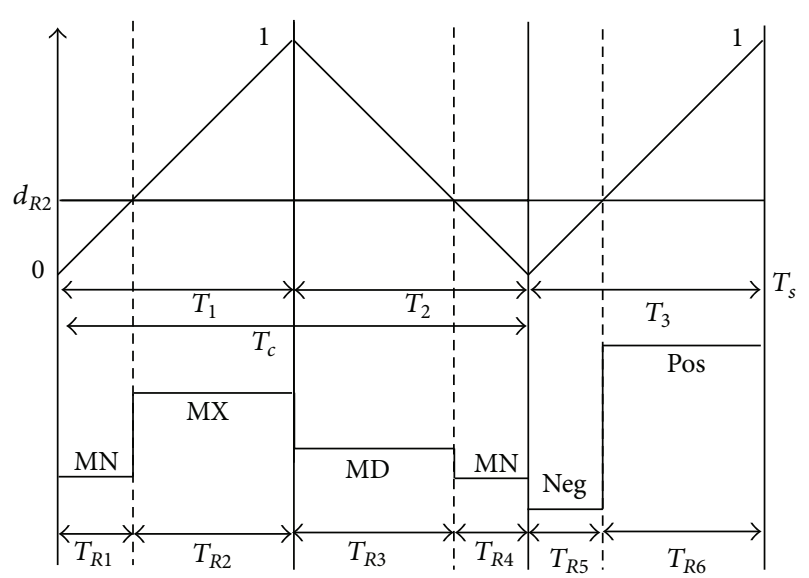

FIgURE 3: Switching pattern II, output $R$ phase switching state.

output terminal, and during $T_{3}$ the input phases of DC battery are connected to a corresponding output terminal. In addition, the time interval $T_{c}$ is divided into two periods, $T_{1}$ and $T_{2}$. Also, the MX, MD, and MN denote the instantaneous values of maximum, medium, and minimum input voltages of AC generator.

Furthermore, POS and NEG denoted the instantaneous values of positive and negative input voltages of DC battery, respectively. During $T_{1}$, the line-to-line voltage between MX and $\mathrm{MN}$ is used, which is the maximum line-to-line voltage among three line-to-line input voltages of generator at the sampling instant. During $T_{2}$, the second maximum line-toline voltage is used which is MX to MD for switching pattern
I and MD to MN for switching pattern II. Finally, during $T_{3}$ the line-to-line voltage between POS and NEG is employed.

2.1. Switching Pattern I. Figure 2 indicates the switching pattern I, where the $R$ phase duty ratio value $\left(d_{R 1}\right)$ is compared with triangular carrier waveform to generate the $R$ phase output voltage. The output phase is changed during the switching pattern I from $\mathrm{MN} \rightarrow \mathrm{MX} \rightarrow \mathrm{MX} \rightarrow \mathrm{MD} \rightarrow$ NEG $\rightarrow$ POS, consequently. As illustrated in Figure 2, the output phase " $R$ " is connected to the input phase "MN" during $T_{R 1}$ and when $T_{s}$ is the sequence switching period. And it is connected to phases "MX," "MX," "MD," "NEG," and "POS" during time periods $T_{R 2}, T_{R 3}, T_{R 4}, T_{R 5}$, and $T_{R 6}$, respectively. These six time subintervals can be represented as (1), where $d_{R 1}$ is the $R$ phase duty ratio value and carrier slops are defined as $m=T_{1} / T_{c}$ and $n=T_{c} / T_{s}$. Consider

$$
\begin{aligned}
& T_{R 1}=d_{R 1} \cdot m \cdot n \cdot T_{s}, \\
& T_{R 2}=\left(1-d_{R 1}\right) \cdot m \cdot n \cdot T_{s}, \\
& T_{R 3}=\left(1-d_{R 1}\right) \cdot(1-m) \cdot n \cdot T_{s}, \\
& T_{R 4}=d_{R 1} \cdot(1-m) \cdot n \cdot T_{s}, \\
& T_{R 5}=d_{R 1} \cdot(1-n) \cdot T_{s}, \\
& T_{R 6}=\left(1-d_{R 1}\right) \cdot(1-n) \cdot T_{s} .
\end{aligned}
$$

The fluctuation of the input voltage is negligible during the switching periods. Thus, the integration of the output voltage $v_{o R}$ over $T_{s}$ can be expressed in

$$
\begin{aligned}
\int_{0}^{T_{s}} v_{o R} d t \cong & T_{R 1} \cdot \mathrm{MN}+\left(T_{R 2}+T_{R 3}\right) \cdot \mathrm{MX}+T_{R 4} \mathrm{MD} \\
& +T_{R 5} \cdot \mathrm{NEG}+T_{R 6} \cdot \mathrm{POS} .
\end{aligned}
$$

Based on (1) and (2), the average output voltage can be expressed in terms of $m$ and $n$ as presented in

$$
\begin{aligned}
\bar{v}_{\mathrm{OR}} & =\frac{1}{T_{s}} \int_{0}^{T_{s}} v_{o R} d t \cong d_{R 1}(-(1-n) \cdot \mathrm{POS}-n \cdot \mathrm{MX} \\
& +(1-m) \cdot n \cdot \mathrm{MD}+m \cdot n \cdot \mathrm{MN}+(1-n) \cdot \mathrm{NEG}) \\
& +n \cdot \mathrm{MX}-(1-n) \cdot \mathrm{POS}
\end{aligned}
$$

Therefore, for present switching cycle, the duty ratio value, $d_{R 1}$, can be written as

$$
d_{R 1}=\frac{\left(v_{o R}^{*}-n \cdot \mathrm{MX}-(1-n) \cdot \mathrm{POS}\right)}{-(1-n) \mathrm{POS}-n \cdot \mathrm{MX}+(1-m) \cdot n \cdot \mathrm{MD}+m \cdot n \cdot \mathrm{MN}+(1-n) \cdot \mathrm{NEG}},
$$

where $v_{o R}^{*}$ is the $R$ phase output voltage command which is equal to $\bar{v}_{O R}$.
2.2. Switching Pattern II. The procedure to drive the equation for switching pattern II is the same as the previous switching 
pattern. Figure 3 illustrates the case of switching pattern II where the $R$ phase duty ratio value $\left(d_{R 2}\right)$ is compared with triangular carrier waveform to generate the $R$ phase output voltage. The output phase is changed during switching pattern II from $\mathrm{MN} \rightarrow \mathrm{MX} \rightarrow \mathrm{MD} \rightarrow \mathrm{MN} \rightarrow \mathrm{NEG} \rightarrow \mathrm{POS}$, consequently.

Similarly, the integration of the output voltage $v_{O R}$ and the average output voltage $\bar{v}_{\mathrm{OR}}$ is presented in

$$
\begin{gathered}
\int_{0}^{T_{s}} v_{o R} d t \cong\left(T_{R 1}+T_{R 4}\right) \cdot \mathrm{MN}+T_{R 2} \cdot \mathrm{MX}+T_{R 3} \cdot \mathrm{MD} \\
\quad+T_{R 5} \cdot \mathrm{NEG}+T_{R 6} \cdot \mathrm{POS}, \\
\bar{v}_{\mathrm{OR}}=\frac{1}{T_{s}} \int_{0}^{T_{s}} v_{o R} d t \cong d_{R 2}(-(1-n) \cdot \mathrm{POS}-m \cdot n \\
\quad \cdot \mathrm{MX}-(1-m) \cdot n \cdot \mathrm{MD}+n \cdot \mathrm{MN}+(1-n) \cdot \mathrm{NEG}) \\
\quad+(1-n) \cdot \mathrm{POS}-m \cdot n \cdot \mathrm{MX}+(1-m) \cdot n \cdot \mathrm{MD} .
\end{gathered}
$$

By letting $\bar{v}_{\mathrm{OR}}$ be equal to $v_{o R}^{*}$ the duty ratio value $d_{R 2}$ can be written as

$$
\begin{aligned}
& d_{R 2}=\left(v_{o R}^{*}-n \cdot \mathrm{MX}-(1-n) \cdot \mathrm{POS}\right)(-(1-n) \cdot \mathrm{POS} \\
& -n \cdot \mathrm{MX}+(1-m) \cdot n \cdot \mathrm{MD}+m \cdot n \cdot \mathrm{MN}+(1-n) \\
& \cdot \mathrm{NEG})^{-1}
\end{aligned}
$$

When the switching state for output phase " $R$ " is POS, NEG, $\mathrm{MX}, \mathrm{MD}$, or $\mathrm{MN}$, the output phase " $R$ " is connected to the input phase voltage POS, NEG, MX, MD, or MN, respectively. In fact, by using logic devices such as FPGA, the circuit for generating the PWM signal can easily be implemented.

It is possible to synthesize the input current and control the power factor in EDDPWM by adjusting the amount of $m$ and $n$, when $m$ and $n$ are related to the maximum and minimum current as represented:

$$
\begin{aligned}
& m \equiv \frac{T_{1}}{T_{c}}=-\frac{i_{s \mathrm{MX}}}{i_{s \mathrm{MN}}}, \\
& n \equiv \frac{T_{c}}{T_{s}}=\frac{i_{s \mathrm{MN}}}{\left(i_{s \mathrm{MN}}-i_{s \mathrm{POS}}\right)} .
\end{aligned}
$$

\section{System Operation Modes}

According to the type and number of outputs and inputs connected to the system, the operation states of SABBPS system can be classified into five possible modes which are listed in Table 1. Whether energy sources provide power for the load or battery, when the converter is connected to the AC load and when the battery bank absorbs or supplies power. In Table 1 the renewable source, supplying power to the battery, or the AC load is defined by "O" or "X." For the battery bank, " $\nabla$ " illustrates a discharge, whereas " $\mathbf{\Delta}$ " illustrates a charge. In addition, the AC load connecting to the MDMC is indicated by "O" or by "X."

Power sources of the MDMC change for different operation modes. In operation mode 1 , power is transferred from
TABLE 1: The operation states of SABBPS.

\begin{tabular}{lccccc}
\hline \multirow{2}{*}{ Parameters } & \multicolumn{5}{c}{ SABBS operation mode } \\
& 1 & 2 & 3 & 4 & 5 \\
\hline Three-phase generator & $\mathrm{O}$ & $\mathrm{O}$ & $\mathrm{O}$ & $\mathrm{X}$ & $\mathrm{O}$ \\
AC load & $\mathrm{O}$ & $\mathrm{O}$ & $\mathrm{X}$ & $\mathrm{O}$ & $\mathrm{O}$ \\
Battery bank & $\mathrm{X}$ & $\boldsymbol{\Delta}$ & $\boldsymbol{\Delta}$ & $\boldsymbol{\nabla}$ & $\boldsymbol{\nabla}$ \\
\hline O = connected, $\mathrm{X}=$ disconnected, $\boldsymbol{\Lambda}$ = charging, and $\boldsymbol{\nabla}=$ discharging.
\end{tabular}

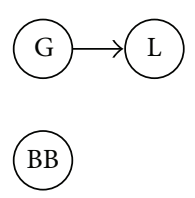

Mode 1

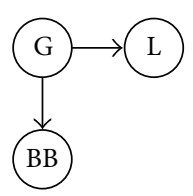

Mode 2

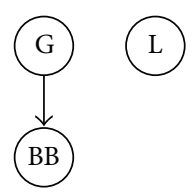

Mode 3

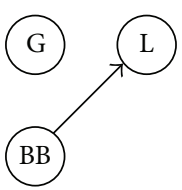

Mode 4

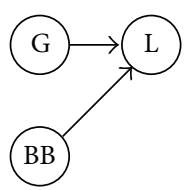

Mode 5
G: generator

L: AC load

BB: battery bank

FIGURE 4: Simplified sketch of the SABBS under different operation modes.

the AC generator to the AC output load. Thus, the battery bank is disconnected from the system and the MDMC acts as three-to-single-phase $\mathrm{AC} / \mathrm{AC}$ converter. In operation mode 2, power is transferred from the AC generator to the battery bank and the AC output load; thus, the MDMC supplies power for the AC load and charges up the battery bank via the charging controller circuit; MDMC acts as inverter and PWM converter. In operation mode 3 , the AC load is disconnected from system; the variable speed turbine only exports energy to the battery bank through the bidirectional switches of the MDMC (just charges up the battery bank). Thus, MDMC works as PWM converter. By following the above analytic approach, other operation modes also can be educated.

Figure 4 indicates the simplified sketch of the stand-alone battery based system under five different operation modes, where " $\mathrm{G}$," "BB," and "L" represent the three-phase generator, the battery bank, and the AC load, respectively.

3.1. Battery Charging. Several methods, such as SOC estimation based on the terminal voltage and internal resistance [29], cell-impedance and impedance variation of cells/batteries [30, 31], error-correction mechanism based on Kalman filter for both state observation and prediction problems [32, 33], SOC estimation based on artificial neural networks [34], and fuzzy logic principles [35], have been reported by researchers to predict SOC. According to [36] the open circuit voltage method is online and cheap and makes it easily to determine SOC in battery based system. Open circuit 


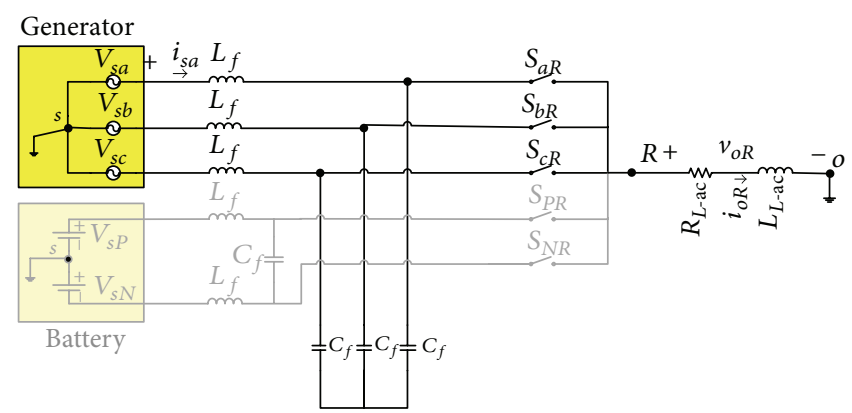

Figure 5: Circuit configuration of MDMC in operation mode 1.

voltage technique for SOC estimation monitors the terminal voltage and current under discharging state to determine the voltage of a battery under load.

The MDMC with EDDPWM method introduced by [27] is able to read the voltage at the DC side continually and monitor the amount of current injection to DC load to determine the SOC and charging the battery. Therefore, the output phases $S$ and $T$ indicated in Figure 1 can be used for battery charging or supplying the DC load. However, the extra charge control circuit should be added to the system to increase the safety and reduce the charging time of system.

\section{Equivalent Circuit of the Converter}

The EDDPWM control method can be applied to the MDMC as a modular structure for each phase where each output phase has the independent reference control signal. This reference control signal can be different in terms of frequency, waveform shape, and amplitude [27]. The MDMC works in operation modes 1,2 , and 3 when the line-to-neutral voltage of AC generator $v_{s \text {-rms }}$ is bigger than battery voltage $v_{s \text {-dc }}$ and works in operation modes 4 and 5 when $v_{s-\mathrm{dc}}$ is bigger than the line-to-neutral $v_{s \text {-rms }}$.

Regarding the semiconductor finite switching times and propagation delays in practical, switches cannot be switched on and off instantaneously in MDMC. In addition, due to the lack of a natural free-wheeling in this structure, reliable current commutation between switches in MDMC is too difficult. Therefore, in this study, current commutation or fourstep commutation method introduced by [37, 38] has been improved based on MDMC structure for safe commutation between an outgoing and an incoming switch. Furthermore, in MDMC, any problem in supplying the current to load can be generated over voltages at output phase. Also, overvoltages can appear from the input side caused by line disturbance. Hence, a clamp circuit introduced by [39] has been modified based on MDMC structure to avoid overvoltages coming from the grid and from the load to the system.

4.1. Operation Mode 1. In this mode, the MDMC acts as three-phase to single-phase matrix converter. The power is transferred through the three bidirectional switches which are connected to input phases $a, b$, and $c$ to output phase $R$. According to switching patterns I and II when $n=1$, the input of MDMC is connected to the AC generator and battery is disconnected from the system. Figure 5 indicates the circuit configuration of MDMC in operation mode 1 with neutral connection.

According to EDDPWM switching method, output terminals can separately be controlled to follow their reference signals. Therefore, the EDDPWM can be used as modular configuration at each output phase. The duty ratio for phase $R$ in operation mode 1 can be represented as (8). Due to the existence of neutral connection in this mode the maximum voltage ratio is limited to $q_{\max }=0.5 . q$ is the voltage ratio of the input terminal voltage to the output terminal voltage $\left(v_{o \text {-rms }} / v_{s-\text { rms }}\right)$. The duty cycle in operation mode 1 for switching pattern I and switching pattern II can be calculated in the same manner of (4) and (6) while $n=1$ in this operation mode. The duty ratio can be represented as follows for switching patterns I and II, respectively:

$$
\begin{aligned}
& d_{R 1}=\frac{v_{o R}^{*}-\mathrm{MX}}{-\mathrm{MX}+(1-m) \cdot \mathrm{MD}+m \cdot \mathrm{MN}}, \\
& d_{R 2}=\frac{v_{o R}^{*}-n \cdot \mathrm{MX}+(1-m) \cdot \mathrm{MD}}{-m \cdot \mathrm{MX}+(-1+m) \cdot \mathrm{MD}+\mathrm{MN}} .
\end{aligned}
$$

The output voltage command $v_{o R}^{*}$ of the converter can be represented as below:

$$
v_{o R}^{*}=\sqrt{\frac{2}{3}} \cdot q \cdot v_{s-\mathrm{rms}} \cdot \sin \left(2 \pi f_{o} t\right),
$$

where $v_{s \text {-rms }}$ is the line-to-line RMS value and $f_{o}$ is the desired output frequency for the corresponding phase.

4.2. Operation Mode 2. In this mode, the MDMC acts as three-phase to single-phase matrix converter [40] (through the switches $S_{a R}, S_{b R}$, and $S_{c R}$ ) and two three-phase to singlephase PWM converter (through the switches $S_{a S}, S_{b S}$, and $S_{c S}$ for output phase $S$ and $S_{a T}, S_{b T}$, and $S_{c T}$ for phase $T$ ). The power is transferred through the nine bidirectional switches which are connected to input phases $a, b$, and $c$ to output phases $R, S$, and $T$. As described in operation mode 1 when $n=1$, the input of MDMC is connected to the AC generator and battery is disconnected from the system. Figure 6 shows the circuit configuration of MDMC in operation mode 2 with three output terminals. 


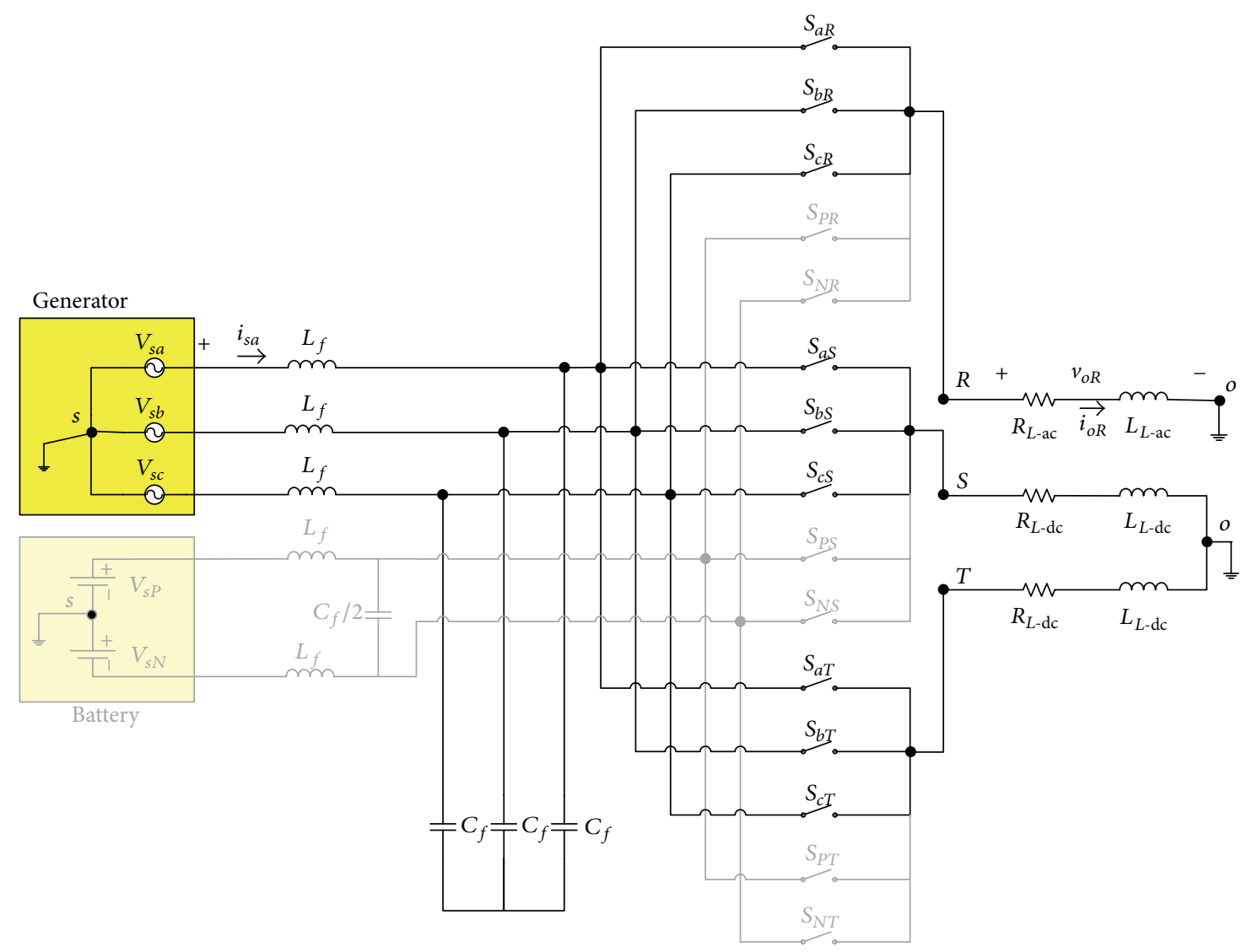

FIgURE 6: Circuit configuration of MDMC in operation mode 2.

Three bidirectional switches are used for each output phase to apply the switching patterns I and II. The POS and NEG input phases are always disconnected while MX, MD, and $\mathrm{MN}$ are selected by instantaneous comparison of the $A C$ input phases. When the switching state for output phase " $R$ " is MX, MD, or MN, the output phase " $R$ " is connected to the input phase where the voltage is MX, MD, or MN, respectively. The duty ratio formula is the same as direct duty PWM presented in [25].

The duty ratio of phases $S$ and $T$ is indicated as $d_{S}$ and $d_{T}$ and can be derived in the same way of phase $R$ by letting $\bar{v}_{O S}$ and $\bar{v}_{O T}$ be equal to the $S$ and $T$ phase voltage commands $v_{o S}^{*}$ and $v_{o T}^{*}$, respectively. The duty ratio for phases $S$ and $T$ can be presented as

$$
\begin{aligned}
& d_{S}=\left\{\begin{array}{l}
d_{S 1}=\frac{v_{o S}^{*}-\mathrm{MX}}{-\mathrm{MX}+(1-m) \cdot \mathrm{MD}+m \cdot \mathrm{MN}} \\
d_{S 2}=\frac{v_{o S}^{*}-n \cdot \mathrm{MX}+(1-m) \cdot \mathrm{MD}}{-m \cdot \mathrm{MX}+(-1+m) \cdot \mathrm{MD}+\mathrm{MN}}
\end{array}\right. \\
& d_{T}=\left\{\begin{array}{l}
d_{T 1}=\frac{v_{o T}^{*}-\mathrm{MX}}{-\mathrm{MX}+(1-m) \cdot \mathrm{MD}+m \cdot \mathrm{MN}} \\
d_{T 2}=\frac{v_{o T}^{*}-n \cdot \mathrm{MX}+(1-m) \cdot \mathrm{MD}}{-m \cdot \mathrm{MX}+(-1+m) \cdot \mathrm{MD}+\mathrm{MN}} .
\end{array}\right.
\end{aligned}
$$

The voltage command for phase $R$ is the same as (10), and the voltage command for phases $S$ and $T$ can be expressed as follows:

$$
v_{o S}^{*}=-v_{o T}^{*}=\sqrt{\frac{2}{3}} \cdot q \cdot v_{s-\mathrm{rms}} .
$$

4.3. Operation Mode 3. In this mode, the MDMC acts as double three-phase to single-phase PWM converter. The power is transferred through the six bidirectional switches which are connected to input phases $a, b$, and $c$ to output phases $S$ and $T$. The time subinterval for AC switch is equal to switching period $\left(T_{c}=T_{s}\right)$, the input of MDMC is connected to the AC generator, and battery is disconnected from the system. Figure 7 illustrates the circuit configuration of MDMC in operation mode 3 when the bidirectional switches connected to phase $R$ are turned off.

The duty ratio for phases $S$ and $T$ can be calculated in the same way as (11). The voltage command is also the same as (12) for phases $S$ and $T$. The DC voltage can be used for DC load or charging the battery through the proper charging circuit.

4.4. Operation Mode 4. In this mode, the MDMC acts as single PWM converter. The power is transferred through the two bidirectional switches which are connected to DC input phases $P$ and $N$ to output phase $R$. The time subinterval for AC switch becomes zero $\left(n=T_{c}=0\right)$, the input 


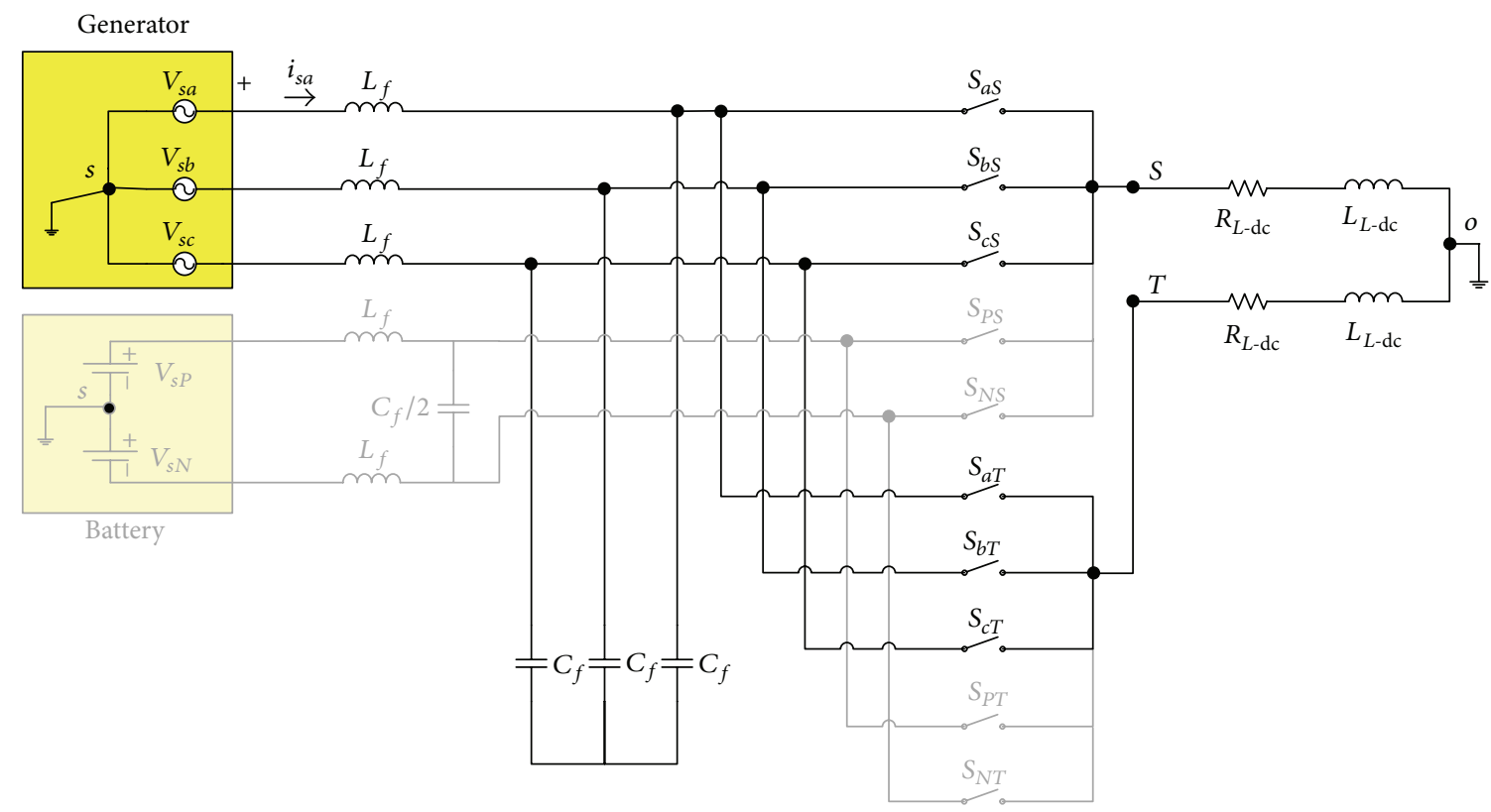

FIgURE 7: Circuit configuration of MDMC in operation mode 3.

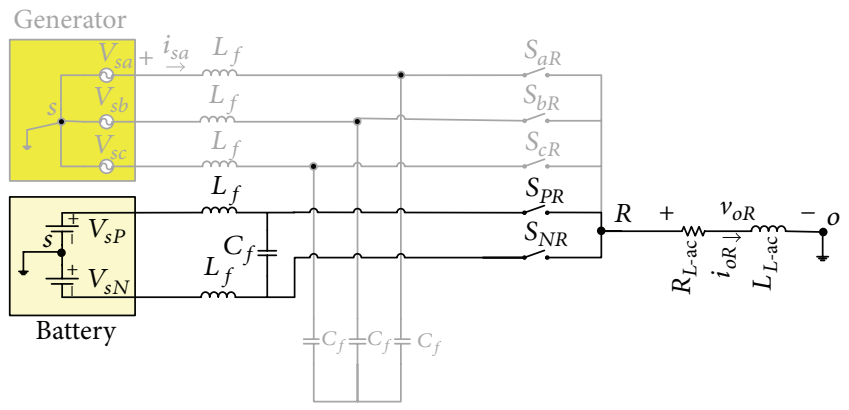

Figure 8: Circuit configuration of MDMC in operation mode 4.

of MDMC is connected to the battery, and AC generator is disconnected from the system. Figure 8 demonstrates the circuit configuration of MDMC in operation mode 4 when the bidirectional switches $S_{P R}$ and $S_{N R}$ are connected to phase $R$.

By putting $n=0$ in (4) and (6), the duty ratio for operation mode 4 in switching patterns I and II can be expressed as below:

$$
d_{R}=\frac{v_{R}^{*}-\mathrm{POS}}{-\mathrm{POS}+\mathrm{NEG}}
$$

when the $v_{R}^{*}$ is

$$
v_{o R}^{*}=\frac{1}{2 \sqrt{2}} \cdot q \cdot v_{s-P N} \cdot \sin \left(2 \pi f_{o} t\right) .
$$

For this operation mode, the voltage ratio can be increased to $1 / \sqrt{2} \approx 0.7$ as the input is connected to DC sources.

4.5. Operation Mode 5. In conventional battery based system when the generator power is less than load demands,

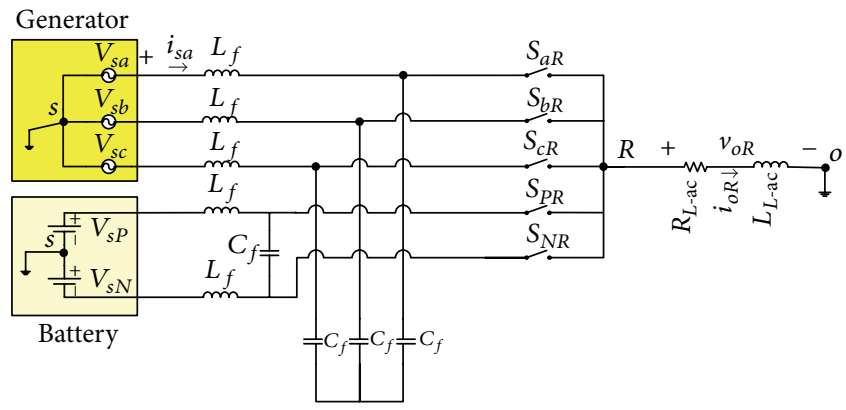

Figure 9: Circuit configuration of MDMC in operation mode 5.

the generator is disconnected from system and battery will supply the system. According to the EDDPWM method, the generator and battery can supply the load, simultaneously. Therefore, in this operation mode, the MDMC acts as fivephase to single-phase converter. The power is transferred through the five bidirectional switches which are connected to $\mathrm{AC}$ and $\mathrm{DC}$ input phases $a, b, c, P$, and $N$ to output phase $R$. The duty ratio of phase $R$ is indicated in (4) and (6) for switching patterns I and II, respectively. The voltage command for phase $R$ can be expressed as follows:

$$
v_{o R}^{*}=\frac{1}{2 \sqrt{2}} \cdot q \cdot v_{s-P N} \cdot \sin \left(2 \pi f_{o} t\right) .
$$

Figure 9 demonstrates the circuit configuration of MDMC in operation mode 5 when the bidirectional switches $S_{a R}, S_{b R}$, $S_{c R}, S_{P R}$, and $S_{N R}$ are connected to phase $R$. For this operation mode, the voltage ratio can be increased to 0.6 as the input is connected to AC and DC sources. 


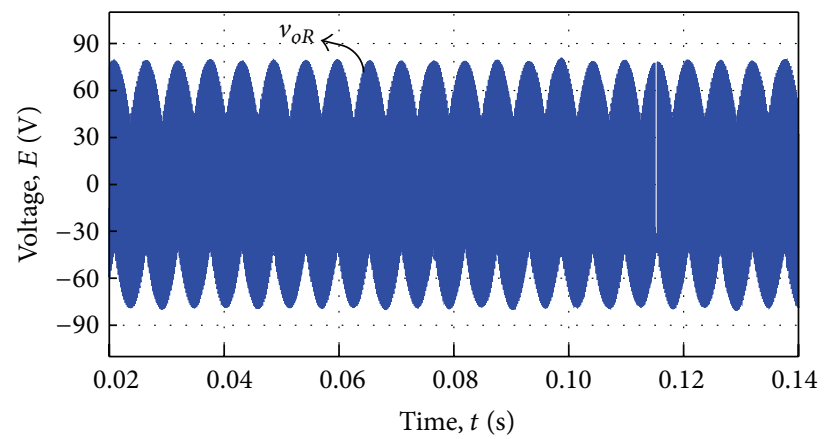

(a) AC output voltage

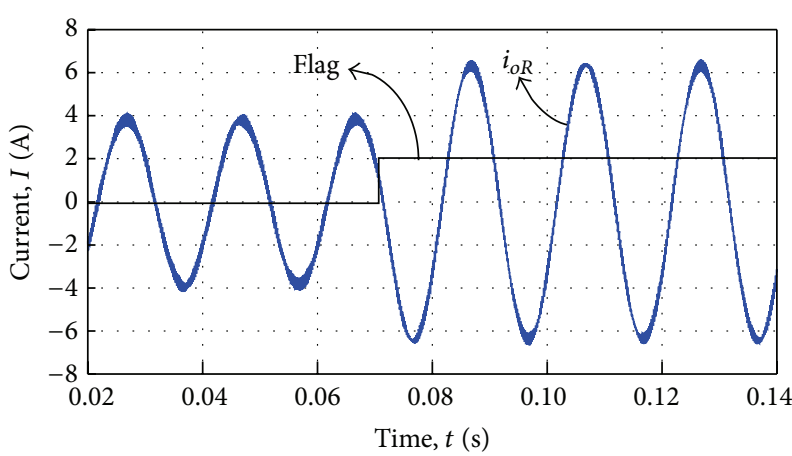

(b) AC output current

FIGURE 10: Simulation waveforms of operation mode 1.

TABLE 2: Simulation parameter.

\begin{tabular}{lc}
\hline Parameter & Value \\
\hline$R$ - $L$ load & $R=5 \Omega, L=10 \mathrm{mH}$ \\
Input filter inductor $L_{f}$ & $100 \mu \mathrm{H}$ \\
Input filter capacitor $C_{f}$ & $60 \mu \mathrm{F}$ \\
Input voltage & $56 \mathrm{~V}$ \\
(line-to-neutral) $V_{s-\text { rms }}$ & \\
$\begin{array}{l}\text { Battery voltage } \\
\text { (line-to-neutral) } V_{s-\mathrm{dc}}\end{array}$ & $\pm 48 \mathrm{~V}$ \\
$\quad \begin{array}{l}\text { Input frequency } f_{s} \\
\quad \text { Output frequency } f_{o}\end{array}$ & $60 \mathrm{~Hz}$ \\
\hline
\end{tabular}

In this mode, the maximum voltage ratio can change within $0.6<q<0.7$ as expressed in (14):

$$
q= \begin{cases}0.7-\left(\frac{k-0.25}{2.5}\right) & \text { for } k>0.25, \\ 0.7-\left(\frac{0.25-k}{2.5}\right) & \text { for } k<0.25\end{cases}
$$

where $k=v_{s-\mathrm{rms}} /\left(v_{s \text {-rms }}+v_{s P}\right)$ indicates the magnitude variation between line-to-neutral RMS value of input AC and DC power supplies and $v_{s \text {-rms }}$ and $v_{s P}$ indicate the RMS value of generator input voltage and DC power supply, respectively.

\section{Results and Discussion}

5.1. Simulation Result. Simulation of the EDDPWM method for MDMC is performed by using MATLAB software. The voltage ratio has been changed in each operation mode to investigate the stability of system. The switching period $T_{s}$ is assumed to be $200 \mu$ s in all operation modes. The simulation parameters shown in Table 2 are the same for all operation modes.

The input line-to-neutral input voltage $\left(V_{s-\text { rms }}\right)$ in operation modes 1,2 , and 3 is bigger than the battery voltage $\left(V_{s \text {-dc }}\right)$ as shown in Table 2. The AC voltage $V_{s \text {-rms }}$ is less than $V_{s \text {-dc }}$ in operation modes 4 and 5 and it is equal to $35 \mathrm{~V}$.
Figure 10 indicates the AC output voltage and current waveforms of proposed MDMC in operation mode 1 , respectively. In this mode the voltage ratio $(q)$ has been increased from 0.3 to 0.5 at time $t=0.07(\mathrm{~s})$. The simulation result indicates that the MDMC is able to reach the maximum voltage ratio $(q=0.5)$ in operation mode 1 without any distortion in output voltage or output current waveforms.

Figures 11(a) and 11(b) illustrate the line-to-line DC output voltage of $v_{O S T}$ and line-to-neutral and AC output voltage of $v_{o R}$. Figure 11(c) shows the simulated responses of MDMC in operation mode 2 when the voltage ratio is changed in AC and DC side at $t=0.07$ and $t=0.09 \mathrm{~s}$, respectively. According to Figure 11(c), the current in $i_{o S}$ and $i_{o T}$ is constant at $t=0.07$ regardless of the changing in $i_{o R}$ which is increased by $0.4 \mathrm{pu}$. In addition, when the voltage ratio for DC phase is reduced from 0.5 to 0.3 , the current in AC side remains constant at $t=0.09 \mathrm{~s}$. The simulation result validates that the proposed EDDPWM is able to track the variation in reference control signal for each phase without disturbing the signal in other output terminals.

Figure 12 indicates the DC output voltage and current waveforms of proposed MDMC in operation mode 3, respectively. In this mode the voltage ratio $(q)$ has been reduced from 0.5 to 0.3 at time $t=0.09(\mathrm{~s})$. The simulation result reveals that the MDMC is able to track the control signal in terms of waveforms, frequency, and amplitude regardless of the type and the number of outputs connected to the system.

Figure 13 illustrates the line-to-neutral AC load voltage and current waveforms in operation mode 3 , respectively. According to Figure 13 the voltage ratio can reach 0.7 in operation mode 4, when the AC power supply is disconnected from the system. The simulation result reveals that the output voltage has been synthesized well with maximum voltage ratio of 0.7 .

Meanwhile, the maximum voltage ratio is equal to 0.5 for operation modes 1,2 , and 3 when the line-to-neutral voltage of AC generator $v_{s \text {-rms }}$ is bigger than battery voltage $v_{s \text {-dc }}$.

In conventional battery based system when the voltage of generator is less than battery voltage, AC power supply will be disconnected from system and demand power will be supplied by battery bank. By using the EDDPWM for $\mathrm{MDMC}$, it is possible to inject the power from AC and DC 


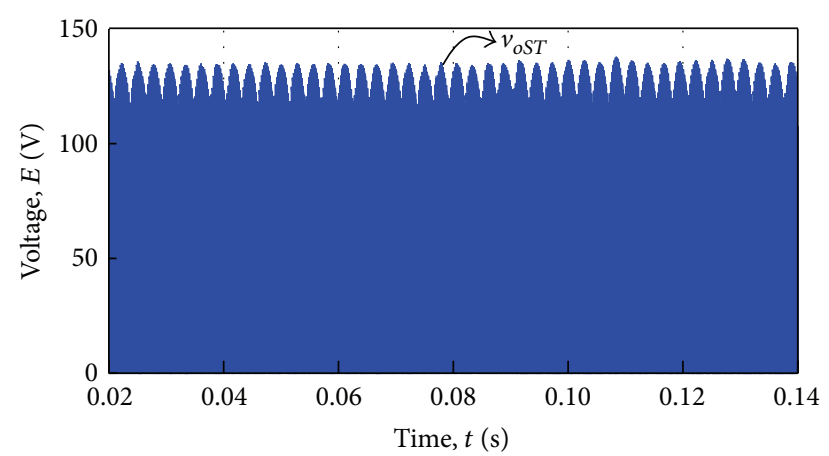

(a) DC output voltage

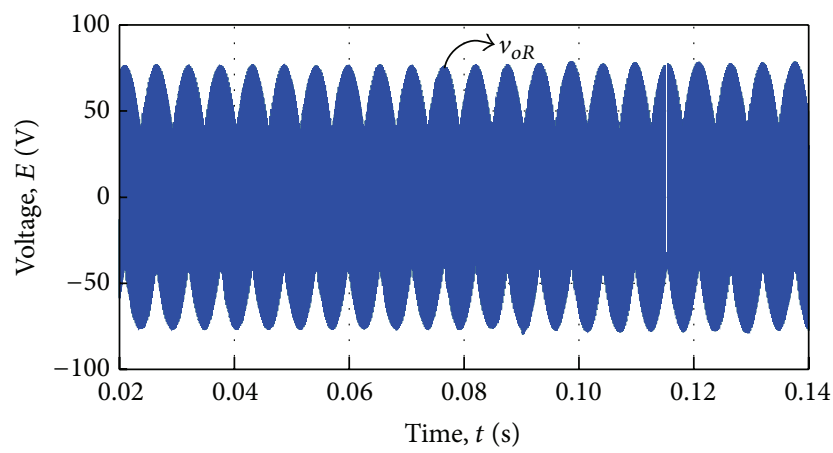

(b) AC output voltage

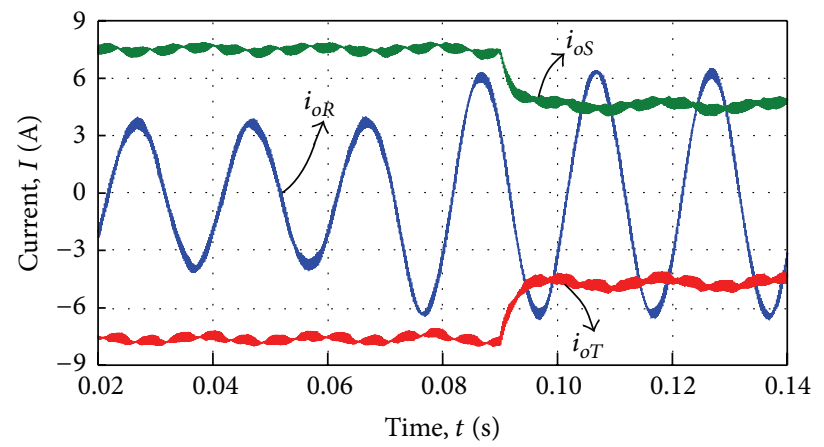

(c) Output current waveforms

FIGURE 11: Simulation waveforms of operation mode 2.

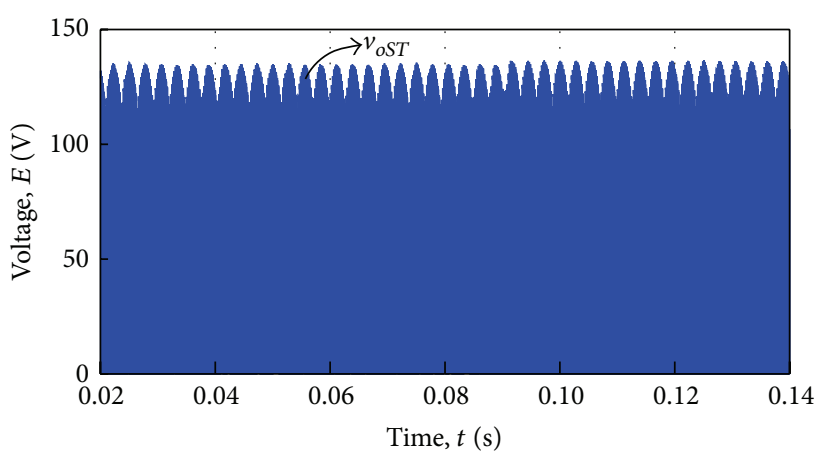

(a) DC output voltage

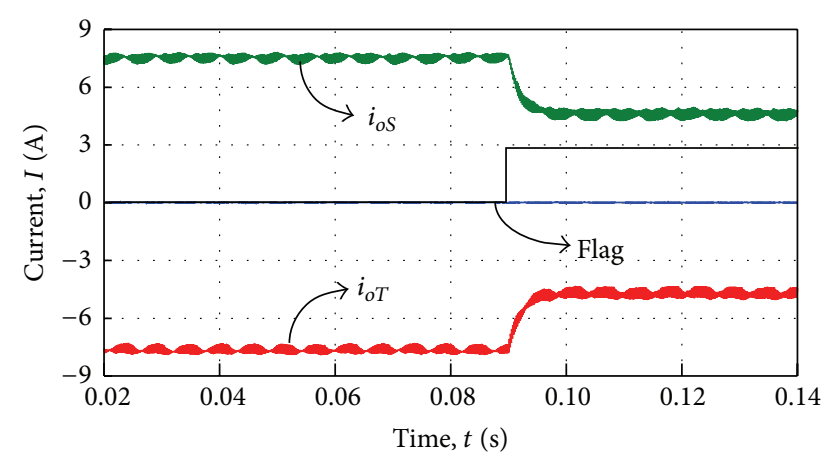

(b) DC output current

FIGURE 12: Simulation waveforms of operation mode 3.

power supply and reach the maximum voltage ratio that is expressed in (12).

Figure 14 indicates the AC output voltage and current waveforms of proposed MDMC in operation mode 5 , respectively. In this mode the voltage ratio $(q)$ has been increased from 0.4 to 0.63 at time $t=0.07$ (s).

It can be clearly seen from Figure 14 that the system is able to track the variation of reference voltage output of terminal $R$. Moreover, the simulation results exhibited that the undershoot/overshoot and steady-state error for output currents are acceptable in all operation modes.
5.2. Experimental Result. To verify the feasibility of the novel EDDPWM method for the proposed MDMC, an experimental setup was built and the EDDPWM controller was implemented using Xilinx Virtex-6 FPGA DSP development kit. Figure 15 shows the experimental setup built in laboratory.

In order to test the stability of the system, reference voltage is changed in AC and DC sides while the loads are constant. Table 3 indicates the experimental parameters of the proposed system when reference voltage is changed. The output voltage variation is not visible in voltage waveform as the switching frequency is high in this modulation method. 


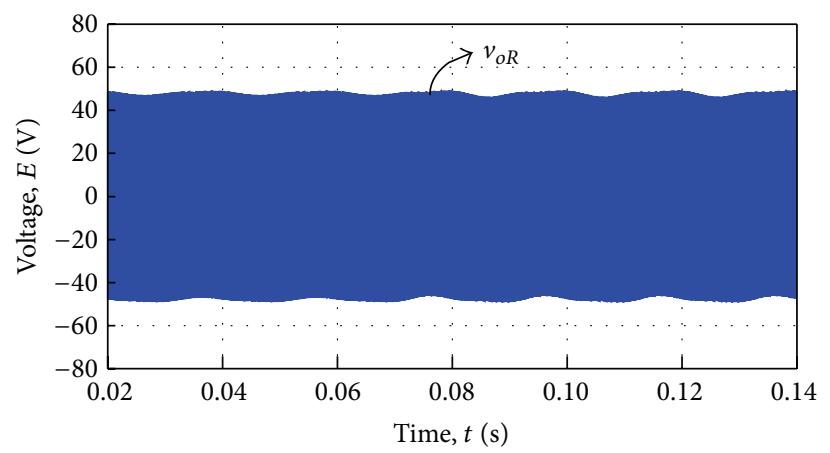

(a) AC output voltage

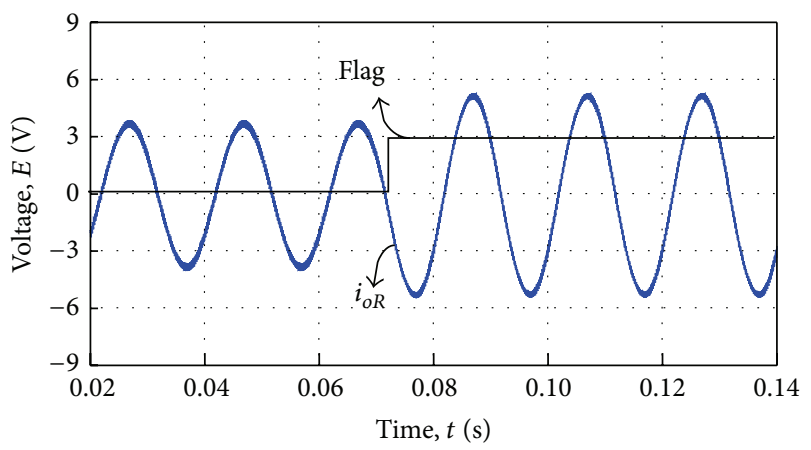

(b) AC output current

FIGURE 13: Simulation waveforms of operation mode 4.

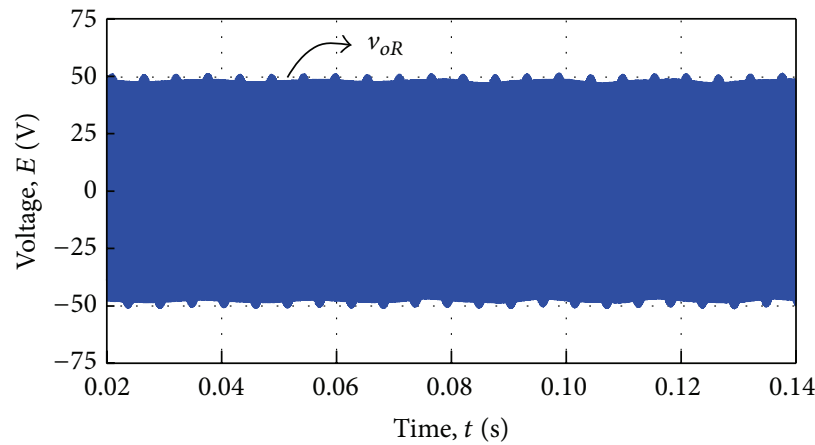

(a) AC output voltage

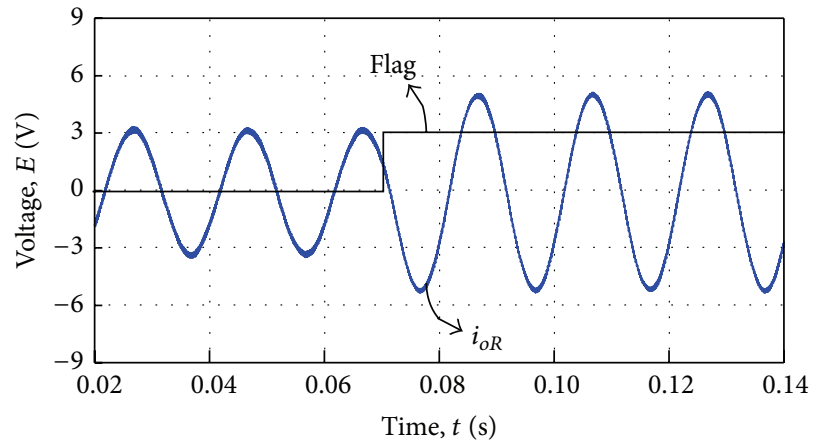

(b) AC output current

FIGURE 14: Simulation waveforms of operation mode 5.

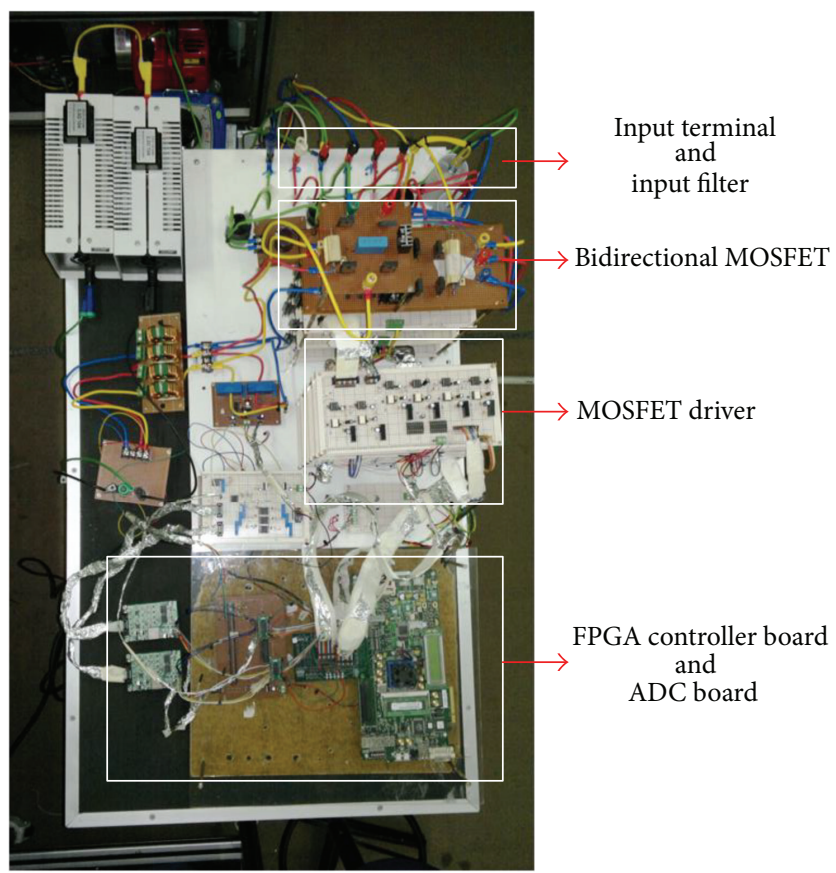

FIGURE 15: Experimental setup of multidirectional matrix converter. 


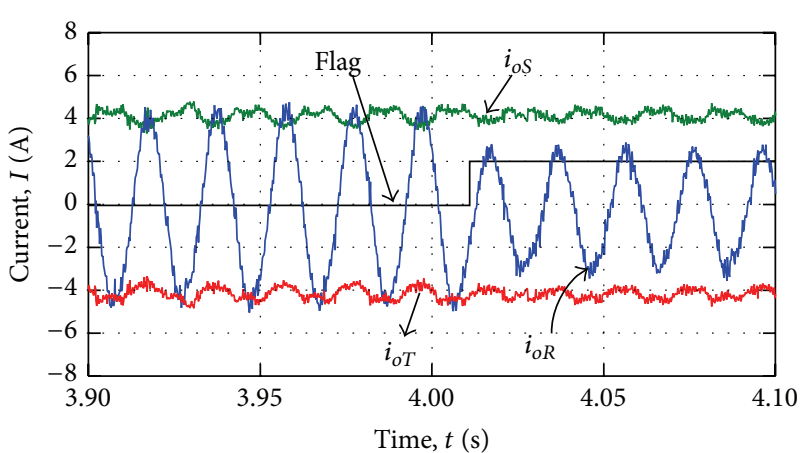

(a) When reference current is reduced by 0.4 pu in phase $R$

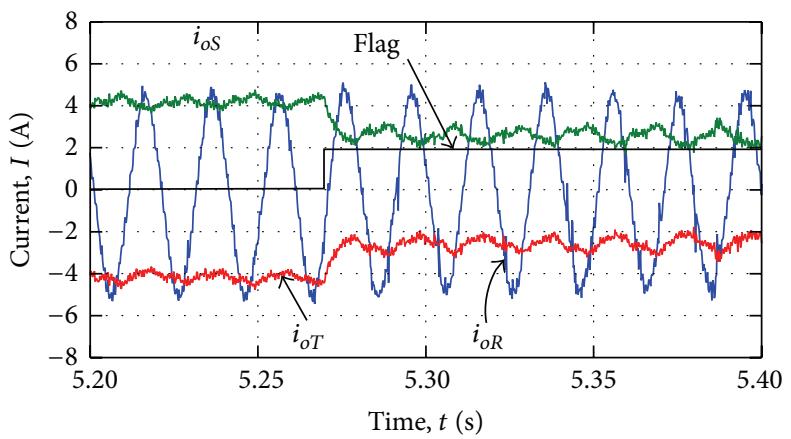

(b) When reference current is reduced by 0.4 pu in phase $S$

FIGURE 16: The dynamic state of experimental waveform: current reference variation.

TABLE 3: Dynamic state experimental parameter and reference voltage variation.

\begin{tabular}{lc}
\hline Parameter & Value \\
\hline$R$ - $L$ load & $R=3.1 \Omega, L=6.4 \mathrm{mH}$ \\
AC input voltage & $30 \mathrm{~V}$ \\
(line-to-neutral RMS) $V_{s-\mathrm{RMS}}$ & $\pm 24 \mathrm{~V}$ \\
DC input voltage $V_{s-\mathrm{dc}}$ & $60 \mathrm{~Hz}$ \\
Input frequency $f_{s}$ & $50 \mathrm{~Hz}$ \\
Output frequency $f_{o}$ & $5 \mathrm{KHz}$ \\
Switching frequency $f_{\text {sw }}$ & $200 \mu \mathrm{s}$ \\
Switching period $T_{s}$ &
\end{tabular}

At constant load the current waveform increases or decreases in accordance with sudden change of reference voltage variation. Figure 16 shows the responses of MDMC when the reference voltage is changed in AC and DC side at $t=4.01 \mathrm{~s}$ and $t=5.27 \mathrm{~s}$, respectively, in operation mode 2 . According to Figure 16(a), the output current $i_{o S}$ remains constant at $t=4.01 \mathrm{~s}$ regardless of the changing in $i_{o R}$ which results in voltage reduction of $0.4 \mathrm{pu}$, where the step change of Flag signal indicates the instant change of the reference voltage. Furthermore, when the DC reference voltage is reduced by $0.4 \mathrm{pu}$, as shown in Figure 16(b), the current in AC side remains constant at $t=5.27 \mathrm{~s}$.

It can clearly be seen from Figure 16 that the system is able to track the variation of reference voltage in each phase separately. The experimental result validates that the reference control signal of each output terminal is independent of other output terminals in terms of frequency, waveform shape, and amplitude. Moreover, the experimental results exhibited that the undershoot/overshoot and dynamic-state error for current waveforms are acceptable for SABBS.

5.3. Total Harmonic Distortion. While there is no national standard dictating total harmonic distortion limits on systems, there are suggested values for acceptable harmonic distortion. IEEE-519 provides recommended harmonic values for power electronic systems. The allowable THD in the input current of the power converter generally is restricted between 10 and $30 \%$ depending on the grid impedance limits [41, 42].

According to IEEE-519 standards, the maximum THD in the grid current cannot exceed 5\% for THD and 3\% for any single harmonic. It is important to note that the recommendations and values given in this standard are purely voluntary. However, keeping low THD values on a system will further ensure proper operation of equipment and a longer equipment life span.

Table 4 compares the DC output current ripple and AC output current THD of simulation and experimental results for MDMC in different operation modes. The results indicated that the THD is different in each operation mode as the number of switches, type of input/output, and input voltage and frequency have been varied in each operation mode. Furthermore, the nonideal characteristic of component, total propagation delay of system, inherent noise and distortion of input power supply, and finite switching times in practical could be the reason for THD gap between the experimental and simulation results. In addition, both generator and DC power supply in experimental setup have some noise and distortion which have direct effect on system performance and output waveform quality.

According to Table 4 and waveform result, the highest THD and ripple appear in operation mode 2 as the AC and DC appear in output phase together. The THD in operation mode 5 is less than other operation modes since 5 bidirectional switches are used to supply the load. In addition, in operation mode 5 the $\mathrm{AC}$ voltage is less than the $\mathrm{DC}$ voltage and input current has been synthesized by adjusting two variables, $n$ and $m$. Therefore, the input current distortion is compensated by proper switching between the two input power supplies.

\section{Conclusion}

This paper presents a systematic approach for MDMC based on the power flow direction among the input and output ports to enhance the performance of stand-alone battery based system and to achieve the continuous power transmission. According to the proposed power flow strategy, the connected 
TABLE 4: Experimental and simulation distortions comparison.

\begin{tabular}{lccccc}
\hline Parameter & Operation mode 1 & Operation mode 2 & Operation mode 3 & Operation mode 4 & Operation mode 5 \\
\hline Simulation THD & $7.22 \%$ & $7.29 \%$ & - & $5.7 \%$ & - \\
Simulation DC current ripple & - & $4.1 \%$ & $3.9 \%$ & - & $139 \%$ \\
Experimental THD & $14.32 \%$ & $14.54 \%$ & - & $13.95 \%$ & - \\
Experimental DC current ripple & - & $11.2 \%$ & $8.7 \%$ & - \\
\hline
\end{tabular}

input and output terminals with corresponding bidirectional switches have been determined to supply the power demand with minimum number of switches. The maximum possible voltage ratio has been calculated in each operation mode. The result validates that the MDMC can work as inverter, PWM converter, or PWM converter and inverter by adjusting the time subinterval in EDDPWM method. In addition, the proposed EDDPWM was able to change the function of the MDMC from inverter to rectifier, rectifier to inverter, rectifier and inverter to inverter, or rectifier based on the operation modes of system.

Particularly, this study exhibited that the maximum voltage ratio is achievable for each operation mode when the undershoot/overshoot and steady-state error for output currents are acceptable in all operation modes. In addition, the quality of output currents has been analysed in terms of THD and ripples.

Based on the literature and result of the present study, as the proposed converter switched from inverter to rectifier in different operation mode, an active power filter can improve the output waveform quality and reduce the noise in input current.

In addition, the modulation control method can be applied to the MDMC as a modular structure for each phase where each output phase has the independent reference control signal. Therefore, the proposed MDMC structure can be used for programmable power supply and extended to the hybrid system with higher number of input and output phases.

\section{Conflict of Interests}

The authors declare that there is no conflict of interests regarding the publication of this paper.

\section{References}

[1] S. Malo and R. Griñó, "Design, construction, and control of a stand-alone energy-conditioning system for PEM-type fuel cells," IEEE Transactions on Power Electronics, vol. 25, no. 10, pp. 2496-2506, 2010.

[2] Y.-M. Chen, Y.-C. Liu, and F.-Y. Wu, "Multi-input DC/DC converter based on the multiwinding transformer for renewable energy applications," IEEE Transactions on Industry Applications, vol. 38, no. 4, pp. 1096-1104, 2002.

[3] L. Solero, A. Lidozzi, and J. A. Pomilio, "Design of multipleinput power converter for hybrid vehicles," IEEE Transactions on Power Electronics, vol. 20, no. 5, pp. 1007-1016, 2005.

[4] A. Iqbal, S. M. Ahmed, and H. Abu-Rub, "Space vector PWM technique for a three-to-five-phase matrix converter," IEEE
Transactions on Industry Applications, vol. 48, no. 2, pp. 697707, 2012.

[5] L. Solero, F. Caricchi, F. Crescimbini, O. Honorati, and F. Mezzetti, "Performance of A $10 \mathrm{~kW}$ power electronic interface for combined wind/PV isolated generating systems," in Proceedings of the 1996 27th Annual IEEE Power Electronics Specialists Conference (PESC '96), pp. 1027-1032, January 1996.

[6] Y.-M. Chen, Y.-C. Liu, F.-Y. Wu, and T.-F. Wu, "Multi-input DC/DC converter based on the flux additivity," in Proceedings of the 36th IAS Annual Meeting. Conference Record of the IEEE Industry Applications Conference, vol. 3, pp. 1866-1873, IEEE, Chicago, Ill, USA, September-October 2001.

[7] Q. Mei, W.-Y. Wu, and Z.-L. Xu, "A multi-directional power converter for a hybrid renewable energy distributed generation system with battery storage," in Proceedings of the 5th CES/IEEE International Power Electronics and Motion Control Conference (IPEMC '06), pp. 1-5, IEEE, Shanghai, China, August 2006.

[8] D. Liu and H. Li, "A ZVS Bi-directional DC-DC converter for multiple energy storage elements," IEEE Transactions on Power Electronics, vol. 21, no. 5, pp. 1513-1517, 2006.

[9] Z. Qian, O. Abdel-Rahman, and I. Batarseh, "An integrated four-port DC/DC converter for renewable energy applications," IEEE Transactions on Power Electronics, vol. 25, no. 7, pp. 18771887, 2010.

[10] P. K. Goel, B. Singh, S. S. Murthy, and N. Kishore, "Isolated wind-hydro hybrid system using cage generators and battery storage," IEEE Transactions on Industrial Electronics, vol. 58, no. 4, pp. 1141-1153, 2011.

[11] M. Venturini and A. Alesina, "The generalised transformera new bidirectional sinusoidal waveform frequency converter with continuously adjustable input power factor," in Proceedings of the Power Electronics Specialists Conference (PESC '80), pp. 242-252, 1980.

[12] A. Alesina and M. G. B. Venturini, "Analysis and design of optimum-amplitude nine-switch direct AC-AC converters," IEEE Transactions on Power Electronics, vol. 4, no. 1, pp. 101-112, 1989.

[13] J. Rodriguez, "A new control technique for AC-AC converters," in Proceedings of the IFAC Control in Power Electronics and Electrical Drives Conference, pp. 203-208, 1983.

[14] P. Ziogas, S. I. Khan, and M. Rashid, "Analysis and design of forced commutated cycloconverter structures with improved transfer characteristics," in Proceedings of the 16th Annual Power Electronics Specialists Conference (PESC '85), Record (A8640426 19-33), pp. 610-622, Institute of Electrical and Electronics Engineers, Toulouse, France, June 1985.

[15] P. D. Ziogas, S. I. Khan, and M. H. Rashid, "Some improved forced commutated cycloconverter structures," IEEE Transactions on Industry Applications, vol. 21, no. 5, pp. 1242-1253, 1985.

[16] G. Kastner and J. Rodriguez, "A forced commutated cycloconverter with control of the source and load currents," in Proceedings of the European Conference on Power Electronics and Applications (EPE '85), pp. 1141-1146, 1985. 
[17] L. Huber and D. Borojevic, "Space vector modulator for forced commutated cycloconverters," in Proceedings of the Conference Record of the IEEE Industry Applications Society Annual Meeting, vol. 1, pp. 871-876, San Diego, Calif, USA, October 1989.

[18] L. Huber and D. Borojevic, "Space vector modulated threephase to three-phase matrix converter with input power factor correction," IEEE Transactions on Industry Applications, vol. 31, no. 6, pp. 1234-1246, 1995.

[19] L. Huber, D. Borojevic, and N. Burany, "Digital implementation of the space vector modulator for forced commutated cycloconverters," in Proceedings of the 4th International Conference on Power Electronics and Variable-Speed Drives, pp. 63-68, July 1990.

[20] L. Huber, D. Borojevic, X. F. Zhuang, and F. C. Lee, "Design and implementation of a three-phase to three-phase matrix converter with input power factor correction," in Proceedings of the 8th Annual Applied Power Electronics Conference and Exposition (APEC '93), pp. 860-865, IEEE, San Diego, Calif, USA, March 1993.

[21] L. Huber, N. Burány, and D. Borojević, "Analysis, design and implementation of the space-vector modulator for forcedcommutated cycloconvertors," IEE Proceedings B: Electric Power Applications, vol. 139, no. 2, pp. 103-113, 1992.

[22] L. Wei and T. A. Lipo, "A novel matrix converter topology with simple commutation," in Proceedings of the 36th IAS Annual Meeting-Conference Record of the Industry Applications, pp. 1749-1754, October 2001.

[23] L. Wei, T. A. Lipo, and H. Chan, "Matrix converter topologies with reduced number of switches," in Proceedings of the IEEE 33rd Annual Power Electronics Specialists Conference (PESC '02), pp. 57-63, June 2002.

[24] Y.-D. Yoon and S.-K. Sul, "Carrier-based modulation technique for matrix converter," IEEE Transactions on Power Electronics, vol. 21, no. 6, pp. 1691-1703, 2006.

[25] Y. Li, N.-S. Choi, B.-M. Han, K. M. Kim, B. Lee, and J.-H. Park, "Direct duty ratio pulse width modulation method for matrix converters," International Journal of Control, Automation and Systems, vol. 6, no. 5, pp. 660-669, 2008.

[26] Y. Li and N.-S. Choi, "Carrier based pulse width modulation for matrix converters," in Proceedings of the 24th Annual IEEE Applied Power Electronics Conference and Exposition (APEC '09), pp. 1709-1715, 2009.

[27] S. Toosi, N. Misron, T. Hanamoto, I. B. Aris, M. A. Mohd Radzi, and H. Yamada, "Novel modulation method for multidirectional matrix converter," The Scientific World Journal, vol. 2014, Article ID 645734, 12 pages, 2014.

[28] N. Yamamura, M. Ishida, and T. Hori, "A simple wind power generating system with permanent magnet type synchronous generator," in Proceedings of the 3rd IEEE International Conference on Power Electronics and Drive Systems (PEDS '99), pp. 849-854, July 1999.

[29] S. Sato and A. Kawamura, "A new estimation method of state of charge using terminal voltage and internal resistance for lead acid battery," in Proceedings of the Power Conversion Conference (PCC-Osaka '02), vol. 2, pp. 565-570, IEEE, Osaka, Japan, 2002.

[30] F. Huet, "A review of impedance measurements for determination of the state-of-charge or state-of-health of secondary batteries," Journal of Power Sources, vol. 70, no. 1, pp. 59-69, 1998.

[31] S. Rodrigues, N. Munichandraiah, and A. K. Shukla, "Review of state-of-charge indication of batteries by means of a.c. impedance measurements," Journal of Power Sources, vol. 87, no. 1, pp. 12-20, 2000.

[32] O. Barbarisi, F. Vasca, and L. Glielmo, "State of charge Kalman filter estimator for automotive batteries," Control Engineering Practice, vol. 14, no. 3, pp. 267-275, 2006.

[33] R. E. Kalman, "A new approach to linear filtering and prediction problems," Journal of Basic Engineering, vol. 82, no. 1, pp. 35-45, 1960.

[34] C. C. Chan, E. W. C. Lo, and S. Weixiang, "The available capacity computation model based on artificial neural network for leadacid batteries in electric vehicles," Journal of Power Sources, vol. 87, no. 1, pp. 201-204, 2000.

[35] A. J. Salkind, C. Fennie, P. Singh, T. Atwater, and D. E. Reisner, "Determination of state-of-charge and state-of-health of batteries by fuzzy logic methodology," Journal of Power Sources, vol. 80, no. 1, pp. 293-300, 1999.

[36] S. Piller, M. Perrin, and A. Jossen, "Methods for state-of-charge determination and their applications," Journal of Power Sources, vol. 96, no. 1, pp. 113-120, 2001.

[37] L. C. Herrero, S. de Pablo, F. Martín, J. M. Ruiz, J. M. González, and A. B. Rey, "Comparative analysis of the techniques of current commutation in matrix converters," in Proceedings of the IEEE International Symposium on Industrial Electronics (ISIE '07), pp. 521-526, June 2007.

[38] P. W. Wheeler, J. Rodríguez, J. C. Clare, L. Empringham, and A. Weinstein, "Matrix converters: a technology review," IEEE Transactions on Industrial Electronics, vol. 49, no. 2, pp. 276288, 2002.

[39] C. L. Neft, "AC power supplied static switching apparatus having energy recovery capability," Google Patents, 1987.

[40] N. Nguyen-Quang, D. A. Stone, C. M. Bingham, and M. P. Foster, "A three-phase to single-phase matrix converter for high-frequency induction heating," in Proceedings of the 13th European Conference on Power Electronics and Applications (EPE '09), pp. 1-10, September 2009.

[41] A. K. Sahoo, A. Shahani, K. Basu, and N. Mohan, "LCL filter design for grid-connected inverters by analytical estimation of PWM ripple voltage," in Proceedings of the 29th Annual IEEE Applied Power Electronics Conference and Exposition (APEC'14), pp. 1281-1286, March 2014.

[42] A. K. Sahoo, K. Basu, and N. Mohan, "Comparison of filter components of back-to-back and matrix converter by analytical estimation of ripple quantities," in Proceedings of the 39th Annual Conference of the IEEE Industrial Electronics Society (IECON '13), pp. 4831-4837, November 2013. 


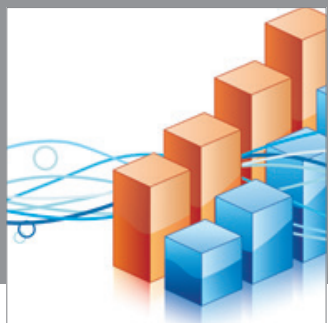

Advances in

Operations Research

mansans

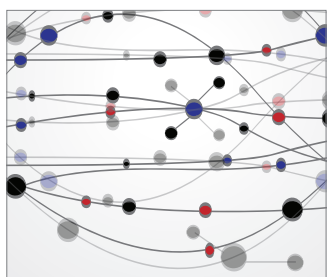

The Scientific World Journal
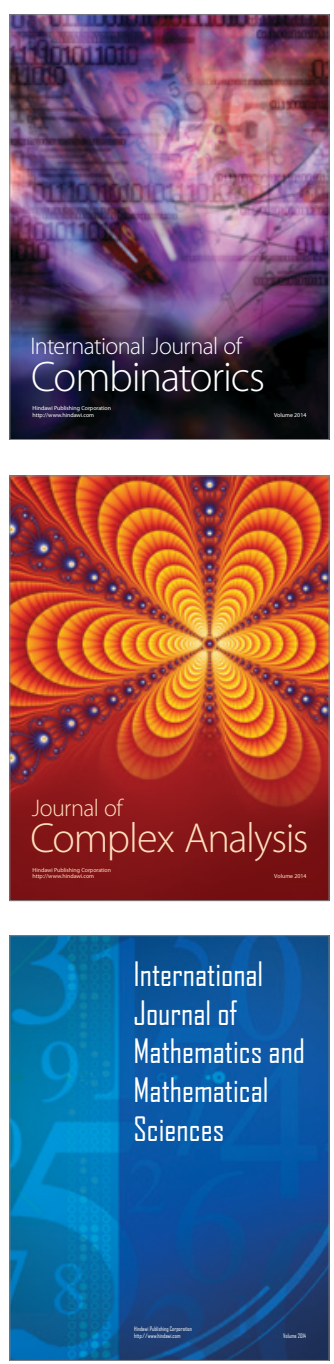
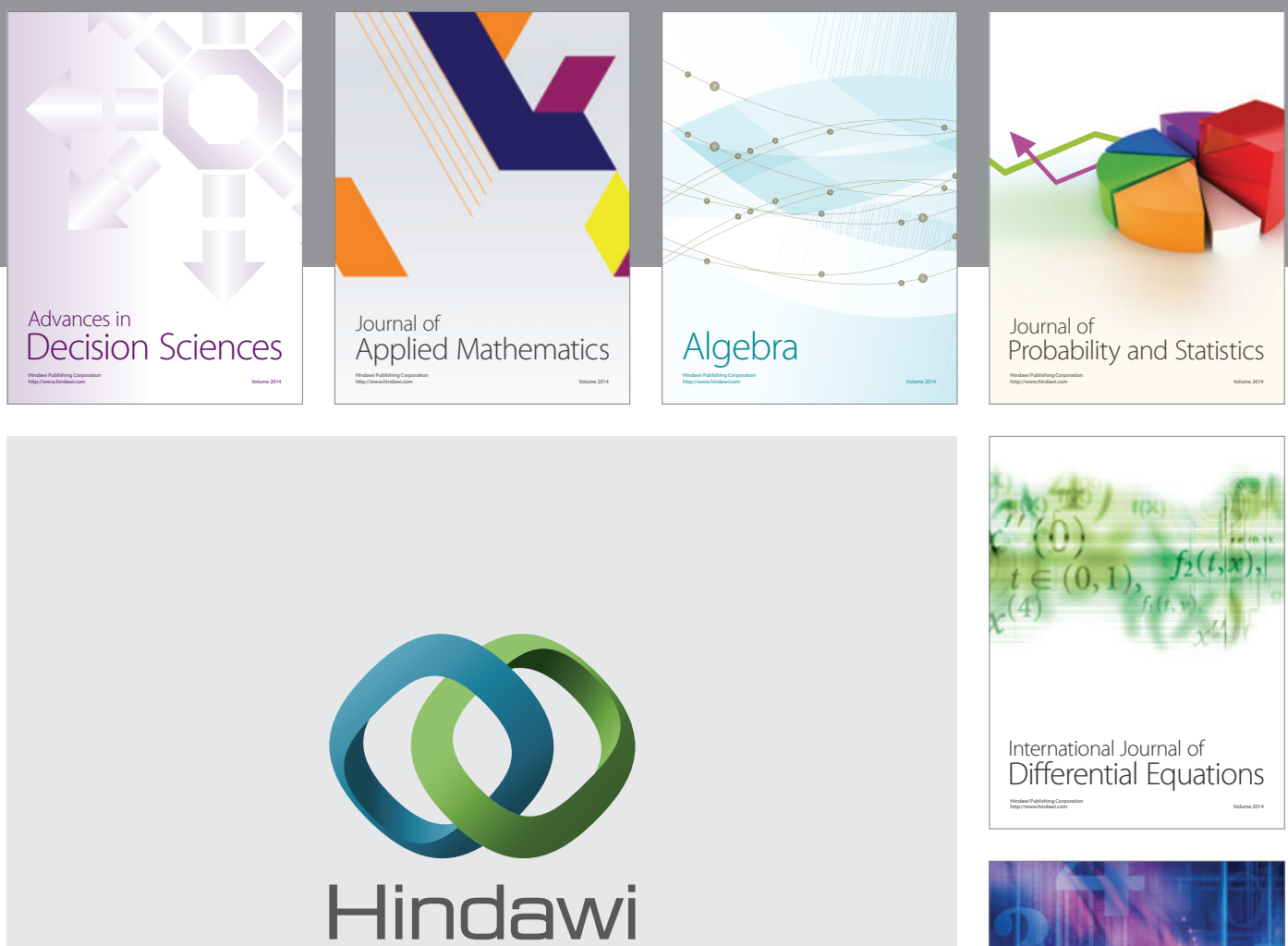

Submit your manuscripts at http://www.hindawi.com
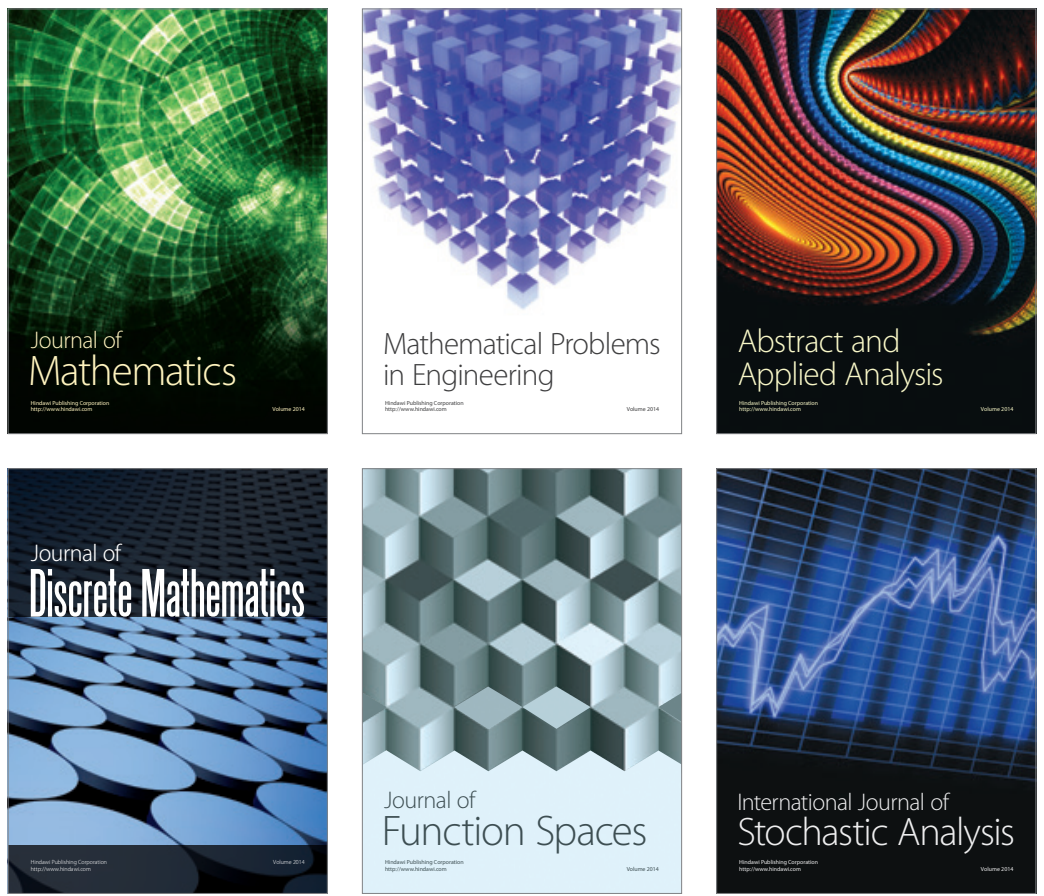

Journal of

Function Spaces

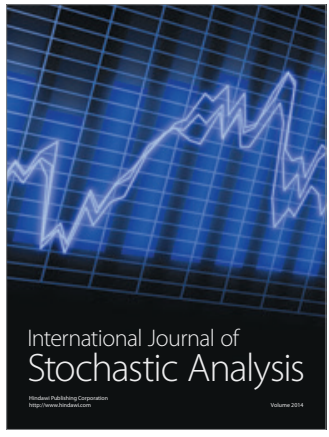

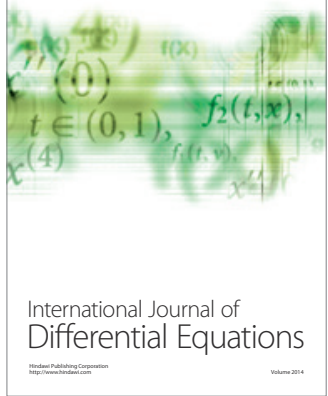
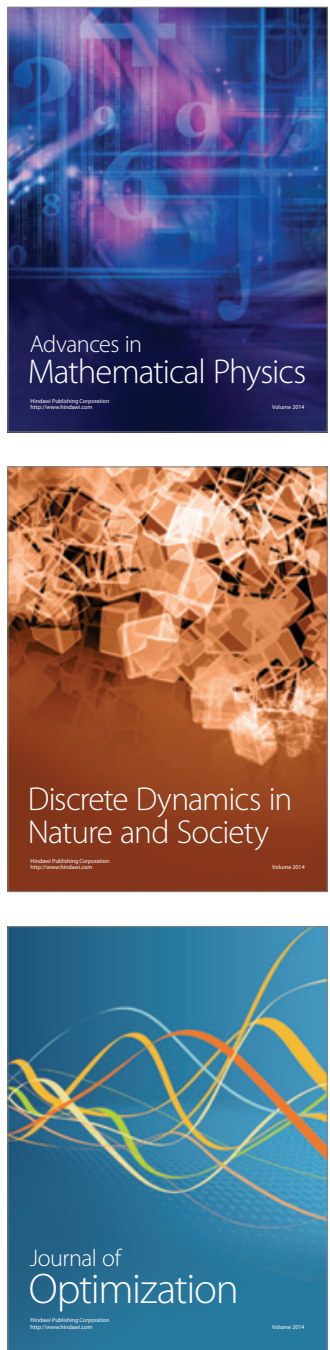